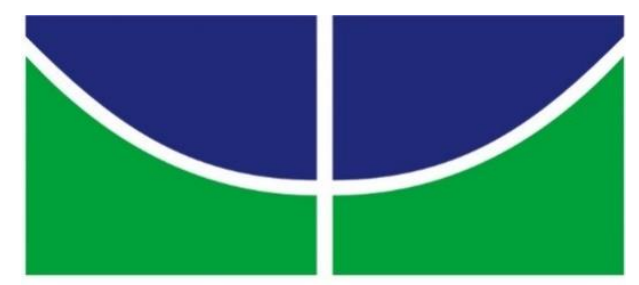

UNIVERSIDADE DE BRASÍLIA

Faculdade de Agronomia e Medicina Veterinária

Programa de Pós-Graduação em Saúde Animal

\title{
ESTUDO DA INFECÇÃO POR HEMOPLASMAS EM CANÍDEOS E FELÍDEOS SELVAGENS DE CATIVEIRO
}

FILIPE TAVARES CARNEIRO

DISSERTAÇÃO DE MESTRADO EM SAÚDE ANIMAL

\author{
BRASÍLIA/DF \\ DEZEMBRO/2015
}




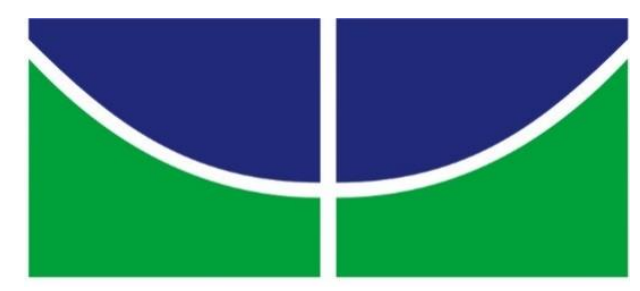

UNIVERSIDADE DE BRASÍLIA

Faculdade de Agronomia e Medicina Veterinária

Programa de Pós-Graduação em Saúde Animal

\section{ESTUDO DA INFECÇÃO POR HEMOPLASMAS EM CANÍDEOS E FELÍDEOS SELVAGENS DE CATIVEIRO}

FILIPE TAVARES CARNEIRO

ORIENTADORA: GIANE REGINA PALUDO

DISSERTAÇÃO DE MESTRADO EM SAÚDE ANIMAL

PUBLICAÇÃO: 116

BRASÍLIA/DF

DEZEMBRO/2015 
ESTUDO DA INFECÇĀO POR HEMOPLASMAS EM CANIDEOS E FELÍDEOS SELVAGENS DE CATIVEIRO

FILIPE TAVARES CARNEIRO

DISSERTAÇĀO DE MESTRADO SUBMETIDA AO PROGRAMA DE PÓS-GRADUAÇÃO EM SAÚDE ANIMAL, COMO PARTE DOS REQUISITOS NECESSÁRIOS A OBTENÇÃO DO GRAU DE MESTRE EM SAÚDE ANIMAL

APROVADA POR:

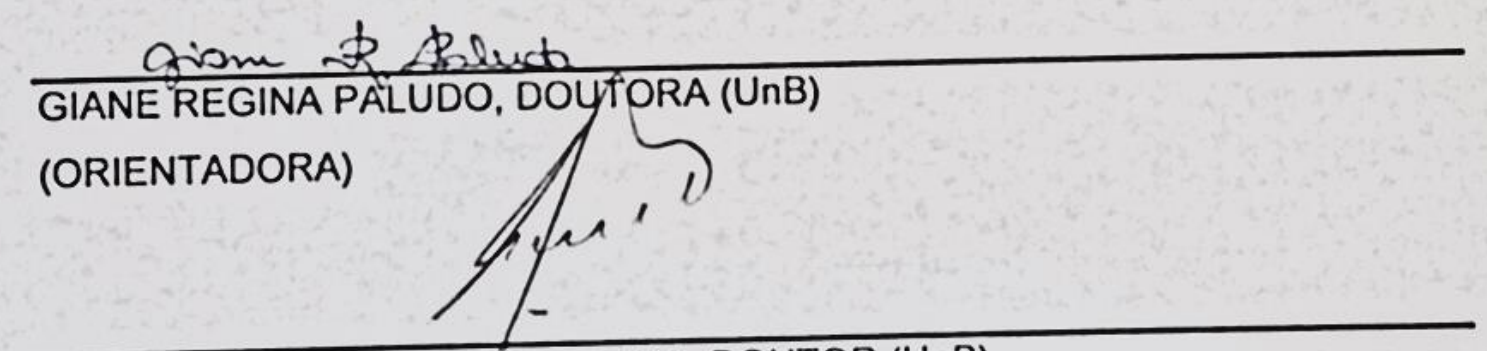

MARCELO ISMAR SILVASANTANA, DOUTOR (UnB)

(EXAMINADOR INTERNO)

Nauiana becht MARIANA MACHADO HECHT, DOUTORA (UnB)

(EXAMINADORA EXTERNA)

BRASILIANDF, 7 DE DEZEMBRO DE 2015. 


\section{REFERÊNCIA BIBLIOGRÁFICA E CATALOGAÇÃO}

CARNEIRO, F. T. Estudo da infecção por hemoplasmas em canídeos e felídeos selvagens de cativeiro. Brasília, Faculdade de Agronomia e Medicina Veterinária, Universidade de Brasília, 2015. Dissertação de Mestrado.

Documento formal, autorizando reprodução desta dissertação de Mestrado para empréstimo ou comercialização, exclusivamente para fins acadêmicos; foi passado pelo autor à Universidade de Brasília e achase arquivado na secretaria do Programa. $O$ autor reserva para si os outros direitos autorais, de publicação. Nenhuma parte desta dissertação de mestrado pode ser reproduzida sem a autorização por escrito do autor. Citações são estimuladas, desde que citada a fonte.

\section{FICHA CATALOGRÁFICA}

Carneiro, Filipe Tavares

Estudo da infecção por hemoplasmas em canídeos e felídeos selvagens de cativeiro/Filipe Tavares Carneiro

Orientação de Giane Regina Paludo

Brasília, 2015. 30p

Dissertação de Mestrado (M) - Universidade de Brasília/ Faculdade de Agronomia e Medicina Veterinária

1.Micoplasmas hemotrópicos. 2.Carnívoros selvagens. 3.Hemoparasitas I. Paludo, G. R. II. Doutor 


\section{RESUMO}

Hemoplasmas são bactérias que prendem-se frouxamente à membrana plasmática de eritrócitos, podendo parasitar mamíferos domésticos e selvagens. Felídeos são conhecidamente parasitados por Mycoplasma haemofelis, Candidatus Mycoplasma haemominutum e Candidatus Mycoplasma turicensis, enquanto canídeos são infectados por pelo menos duas espécies de hemoplasmas: Mycoplasma haemocanis e Candidatus Mycoplasma haematoparvum. As hemoplasmoses são de grande relevância na clínica veterinária, tanto por sua distribuição cosmopolita e severidade de sinais clínicos, a depender da espécie do parasita e imunocompetência do hospedeiro, quanto pelo seu potencial zoonótico e de infecção de animais selvagens ameaçados de extinção. O presente trabalho se propôs a investigar quais espécies de hemoplasmas parasitam as diferentes espécies de carnívoros de cativeiro, a fim de esclarecer a epidemiologia da doença nestas espécies. Além disso, a pesquisa visou caracterizar as alterações hematológicas causadas pela infecção por diferentes espécies de micoplasmas hemotrópicos, a fim de estabelecer sua importância clínica para as espécies selvagens e a capacidade dessas espécies de se tornarem reservatório dos agentes estudados. Foram investigadas as amostras de 33 felídeos e 18 canídeos selvagens e observou-se que a ocorrência da infecção por hemoplasmas nessas espécies é de $45,5 \%$ e $83,3 \%$, respectivamente. Fatores como faixa etária, gênero ou presença de anemia não apresentaram correlação com a positividade para a infecção. Sendo assim, conclui-se que a infecção por hemoplasmas em carnívoros 
selvagens tem alta prevalência, a patogenicidade dos agentes é baixa, ou o estágio crônico é mais frequente, resultando na redução de seu diagnóstico. 


\begin{abstract}
Hemoplasmas are bacteria able to adhere themselves loosely to the plasma membrane of erythrocytes and may parasitize several species of mammals. There are three known species of hemoplasmas that parasitize domestic and wild cats: Mycoplasma haemofelis, Candidatus Mycoplasma haemominutum and Candidatus Mycoplasma turicensis. Dogs are infected by at least two species of hemoplasmas: Candidatus Mycoplasma haematoparvum and Mycoplasma haemocanis. The hemoplasmoses are very important in the veterinary clinic, either because of its worldwide distribution and severity of clinical signs, depending on parasite species and host immune competence, or due to its zoonotic potential and capability of infecting endangered species. This study set out to investigate which hemoplasmas species parasitize different species of captive wild carnivores in order to clarify the epidemiology of the disease in these species. Furthermore, the research intended to characterize the hematological changes caused by different species of hemotrophic mycoplasmas infection in order to establish their clinical importance to wild species and the capacity of these species to become a reservoir of studied agents. Samples of 33 wild felids and 18 wild canids were investigated and it was observed that the occurrence of hemoplasma infection in these species is $45.5 \%$ and $83.3 \%$, respectively. Factors such as age, gender or anemia are not more frequent in animals positive for the infection. Therefore, it is concluded that infection by hemoplasmas in wild carnivores has high prevalence, and either agent pathogenicity is low, or chronic stage is more frequent, resulting in the reduction of diagnosis.
\end{abstract}


Tabela

Página

1 Oligonucleotídeos utilizados no controle da extração de DNA e na investigação e identificação de hemoplasmas

2 Concentração/ volume de reagentes utilizados nas diferentes técnicas de PCR agentes

4 Resultado da PCR geral para hemoplasmas por espécie de felídeos

5 Número de animais positivos e negativos para infecção por hemoplasmas correlacionados com o gênero pelo teste Qui-quadrado de Pearson

6 Número de animais positivos e negativos para infecção por hemoplasmas correlacionados com a faixa etária pelo teste Qui-quadrado de Pearson

7 Número de animais positivos e negativos para infecção por hemoplasmas correlacionados com presença ou ausência de anemia pelo teste Qui-quadrado de Pearson

8 Número de animais positivos e negativos

9 Resultado da PCR geral para hemoplasmas por espécie de canídeos 
LISTA DE SIMBOLOS E ABREVIAÇÕES

\begin{tabular}{ll}
${ }^{\circ} \mathrm{C}$ & Graus Celcius \\
$\mu \mathrm{l}$ & Microlitros \\
$\mu \mathrm{M}$ & Micromolar \\
D. & Duração \\
DNA & Ácido desoxirribonucleico \\
dNTP & Trifosfato de desoxirribonucleosídeos \\
EDTA & Ácido etilenodiamino tetra-acético - \\
GAPDH & anticoagulante \\
MgCl 2 & Gliceraldeído-3-fosfato desidrogenase \\
mM & Cloreto de Magnésio \\
PCR & Mili Molar \\
pmol & Polimerase Chain Reaction (Reação em \\
qPCR & Cadeia de Polimerase) \\
rRNA & Picomoles \\
UnB & PCR em tempo real \\
T. & Ácido ribonucleico ribosomal \\
V & Universidade de Brasília \\
& Temperatura \\
& Unidade \\
\hline &
\end{tabular}


SUMÁRIO

RESUMO

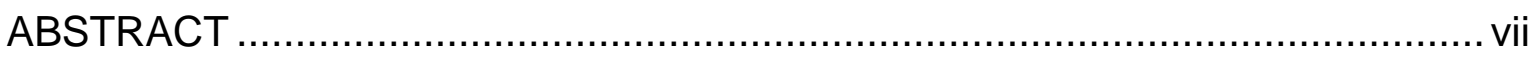

LISTA DE TABELAS …..........................................................................ii

LISTA DE SIMBOLOS E ABREVIAÇÕES .................................................... ix

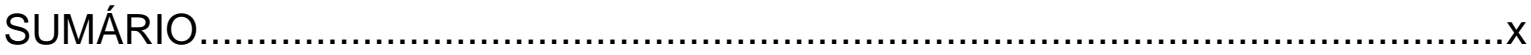

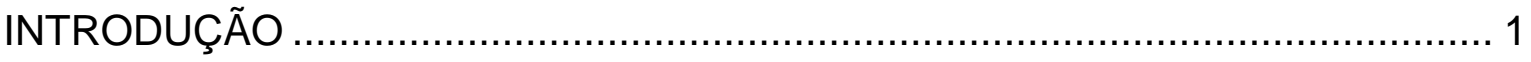

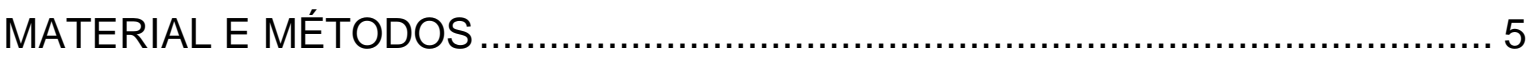

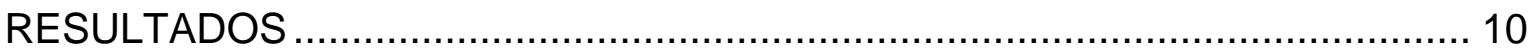

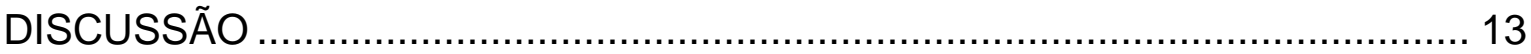

CONCLUSÕES

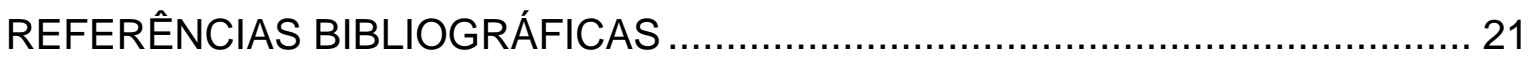


INTRODUÇÃO

Hemoplasmas, ou micoplasmas hemotróficos, são importantes agentes causadores de anemia infecciosa. Originalmente foram enquadrados nos gêneros Haemobartonella ou Eperythrozoon, com base na ocorrência em forma de anéis e presença livre no plasma. Posteriormente, passaram a ser classificados como membros da família Anaplasmataceae, as riquétsias. Porém, a análise do sequenciamento do gene rRNA $16 \mathrm{~S}$ fez com que se notasse sua semelhança ao grupo pulmonar dos micoplasmas, permitindo sua classificação no gênero Mycoplasma (Tasker et al., 2003c; Thrall, 2007; Willi et al., 2007; Biondo et al., 2009).

Espécies de hemoplasmas já foram descritas em todos os continentes, à exceção da Antártida, levando à crença de que este é um microrganismo de distribuição cosmopolita, no entanto a epidemiologia e transmissão desses agentes permanecem um tanto obscuras (Willi et al., 2007; Biondo et al., 2009).

Já que hemoplasmas não podem ser cultivados in vitro, a dose infectante não pode ser medida com precisão experimentalmente e interfere com os resultados. Estudos sugerem que pulgas (Ctenocephalides felis) são responsáveis pela transmissão de Mycoplasma haemofelis e Candidatus Mycoplasma haemominutum em felinos, que o carrapato (Rhipicephalus sanguineus) é o principal vetor de M. haemocanis em cães, que os piolhos (Poliplax serrata e Poliplax spinulosa) são vetores de Mycoplasma coccoides em roedores e que moscas e mosquitos (Stomoxys calcitrans e Aedes aegypti) agem como vetores de 
Mycoplasma suis em suínos (Biondo et al., 2009). Além disso, a literatura sugere infecção por meio de mordeduras, transmissão transmamária e transplacentária e exposição iatrogênica. No último caso, vale ressaltar a infecção de animais esplenectomizados via transfusão sanguínea de um doador infectado ou de receptor com infecção latente (Thrall, 2007).

Existem três espécies conhecidas de hemoplasmas que parasitam felinos domésticos e selvagens, sendo elas Mycoplasma haemofelis, Candidatus Mycoplasma haemominutum e Candidatus Mycoplasma turicensis. Sabe-se que Mycoplasma haemofelis induz anemia mesmo em hospedeiros imunocompetentes, enquanto $\mathrm{Ca}$. M. haeminutum e Ca. M. turicensis aparentam ser menos patogênicos (Haefner et al., 2003; Thrall, 2007; Willi et al., 2007; Santos, 2009; Biondo et al., 2009).

Cães são infectados por, ao menos, duas espécies de hemoplasmas: Mycoplasma haemocanis e Candidatus Mycoplasma haematoparvum (Biondo et al., 2009). Além disso, um hemoplasma canino mais semelhante ao Ca. M. haemominutum que ao $\mathrm{Ca}$. M. haematoparvum foi detectado por reação em cadeia da polimerase (PCR) em um cão em Londrina, e um hemoplasma com 98-100\% de homologia com Ca. M. turicensis encontrado em gatos também amplificou em 7 de 10 cães esplenectomizados em Porto Alegre (Santos, 2009). Não se sabe se tratam-se de novos hemoplasmas caninos ou se canídeos são suscetíveis à infecção por hemoplasmas felinos.

Há relatos de parasitismo por hemoplasmas em diversas espécies selvagens, como, gatos-do-mato-grande (Leopardus geoffroyi), gatos-maracajá (Leopardus wiedii), jaguatiricas (Leopardus pardalis), onças-pardas (Puma concolor), onças-pintadas (Panthera onca), linces-euroasiáticos (Lynx lynx), gatos- 
selvagens (Felis silvestris silvestris), jaguarundis (Puma yagouaroundi), loboscinzentos (Canis lupus) e cachorros-vinagre (Speothos venaticus), inclusive animais considerados vúlneráveis como leões (Panthera leo) e gatos-do-matopequenos (Leopardus tigrinus), ou ameaçados como tigres (Panthera tigris), lincesibéricos (Lynx pardinus) (Haefner et al., 2003; Willi et al., 2006; Guimaraes et al., 2007; André et al., 2011; "The IUCN Red List of Threatened Species," 2016) (Haefner et al., 2003; Willi et al., 2007; Guimaraes et al., 2007; André et al., 2011).

Além disso, já foi descrita na literatura a co-infecção de uma médica veterinária que transitava entre Grenada, Irlanda e África do Sul por Anaplasma platys, Bartonella henselae e Candidatus Mycoplasma haematoparvum. A mulher de 27 anos relatou contato com diversos animais domésticos e selvagens, além de vetores, e apresentou sintomas que variavam de desmaios, dores de cabeça, fotofobia, fasciculações musculares, convulsões tônico-clônicas, ataxia e perda de memória (Maggi et al., 2013).

A infecção direta das hemácias por hemoparasitas pode resultar em anemia intravascular, extravascular ou ainda não causar anemia. Sinais clínicos podem incluir além da anemia hemolítica, esplenomegalia, febre, anorexia, desidratação, emaciação, letargia, icterícia e morte súbita (Thrall, 2007; Willi et al., 2007). A anemia é regenerativa, a menos que haja uma doença primária que iniba a eritropoiese. No caso dos felinos, comumente a hemoplasmose é secundária ao vírus da leucemia felina (FeLV) ou ao vírus da imunodeficiência felina (FIV) (Thrall, 2007).

A identificação de hemoparasitas ocorre tradicionalmente por visualização do esfregaço sanguíneo sob microscopia de luz. No entanto, este método diagnóstico é bastante limitado, pois além de depender muito da quantidade de 
parasita circulante, também sustenta-se da experiência do técnico de laboratório em distinguir o parasita de outras estruturas como corpúsculos de Howell-Jolly, ponteado basofílico ou mesmo artefatos causados por precipitação de corante. Sendo assim, o desenvolvimento de uma reação em cadeia da polimerase (PCR) específica e altamente sensível tem assegurado um diagnóstico eficaz, mesmo em situações em que há apenas uma pequena quantidade do microrganismo parasitando o hospedeiro (Thrall, 2007).

Mesmo sabendo que as hemoplasmoses podem infectar diferentes espécies de carnívoros selvagens e causar sérios sinais clínicos, capazes até mesmo de comprometer a conservação de espécies ameaçadas, existe pouca informação na literatura sobre a ocorrência da infecção por hemoplasmas nessas espécies. Além disso, considerando o potencial zoonótico da doença, é necessário avaliar se existe a probabilidade de animais selvagens funcionarem como reservatórios do agente e transmiti-lo a humanos e animais domésticos.

Os objetivos deste trabalho foram determinar a ocorrência e identificar as espécies de hemoplasmas que acometem os canídeos e felídeos selvagens de cativeiro por meio de PCR convencional. Além disso, objetivou-se verificar as alterações hematológicas ocasionadas pelos hemoplasmas e estudar a epidemiologia da infecção por hemoplasmas em carnívoros correlacionando a prevalência da doença em diferentes espécies selvagens. 


\section{MATERIAL E MÉTODOS}

\section{COLHEITA DAS AMOSTRAS}

Foram utilizadas 33 amostras de sangue de felídeos silvestres e 18 de canídeos silvestres, provenientes da Fundação Jardim Zoológico de Brasília e do Criatório Conservacionista NEx (No Extincion). O zoológico forneceu amostras de três onças-pintadas (Panthera onca), uma jaguatirica (Leopardus pardalis), dois gatos-palheiros (Leopardus pajerus), três onças-pardas (Puma concolor), um gatomaracajá (Leopardus wiedii), um gato-do-mato-pequeno (Leopardus tigrinus), quatro tigres-de-bengala (Panthera tigres), três jaguarundis (Puma yagouaroundl), dois leões-africanos (Panthera leo), seis lobos-guarás (Chrysocyon brachyurus), cinco raposas-do-campo (Lycalopex vetulus), cinco cachorros-do-mato (Cerdocyon thous) e dois cachorros-do-mato-vinagre (Speothos venaticus). O NEx forneceu amostras de oito onças-pintadas, uma jaguatirica, um gato-palheiro e três onças-pardas.

As amostras foram colhidas com autorização da Comissão de Ética no Uso de Animais (CEUA-UnB), conforme UnB-Doc № 130988/2015 e do Institudo

Brasileiro do Meio Ambiente e dos Recursos Naturais Renováveis (IBAMA), conforme SISBIO no 46097.

Também foram utilizadas amostras de sangue de dois cães e quatro gatos domésticos provenientes do atendimento do Hospital Veterinário da UnB e em campanhas de vacinação do Distrito Federal como controles positivos das técnicas 
de PCR. Estes animais haviam sido previamente diagnosticados como portadores de hemoplasmas por meio de PCR em tempo real (qPCR) e sequenciamento e suas amostras encontravam-se armazenadas em um Biobanco no Laboratório de Microbiologia e Patologia Clínica Molecular do Hospital Veterinário da Universidade de Brasília.

Com o objetivo de reduzir o estresse causado pela contenção físico-quimica, todas as amostras de animais selvagens foram colhidas durante procedimentos veterinários de rotina da instituição de origem.

As amostras de sangue venoso foram colhidas por punção da veia cefálica, jugular ou caudal ventral. Essas amostras foram de maneira atraumática e rapidamente acondicionadas em tubos contendo ácido etilenodiaminotetracético (EDTA).

\section{ANÁLISE HEMATOLÓGICA}

As amostras oriundas do Criatório NEX foram encaminhadas ao Laboratório de Patologia Clínica Veterinária do Hospital Veterinário da Universidade de Brasília, onde foi utilizado um contador automático de células para uso veterinário (modelo Horiba ABX Micros ESV 60) para a determinação do número de hemácias, de leucócitos e a concentração de hemoglobina. As amostras oriundas do Zoológico de Brasília foram encaminhadas ao Núcleo de Laboratório do Hospital Veterinário do próprio Zoológico de Brasília, onde foi realizada a contagem manual de hemácias e leucócitos com o auxílio de uma câmara de Neubauer. 
A divergência na metodologia para contagem de leucócitos e hemácias para as amostras de diferentes origens ocorreu a fim de garantir que seu processamento fosse realizado o mais rápido possível. Contudo, um mesmo analisador realizou o processamento das amostras a fim de reduzir variações ao máximo.

O restante do processamento foi idêntico para as amostras de ambas as origens. O volume globular (VG) foi determinado pela técnica do microhematócrito e foram ainda preparados esfregaços de sangue total corados com corante tipo Romanowsky (Panótico Rápido) para a realização do diferencial leucocitário, observação morfológica das células sangüíneas e pesquisa de hemoparasitas.

\section{EXTRAÇÃO DE DNA}

Após a realização dos hemogramas, as amostras com EDTA foram congeladas e encaminhadas ao Laboratório de Microbiologia e Patologia Clínica Molecular do Hospital Veterinário da Universidade de Brasília, onde o DNA foi extraído com a utilização de kits comerciais (Illustra blood genomicPrep Mini Spin $\mathrm{Kit}^{\circledR}, \mathrm{GE}$ Healthcare do Brasil Ltda, São Paulo, SP), seguindo as recomendações do fabricante. As amostras de DNA foram mantidas a $-20^{\circ} \mathrm{C}$ até o momento da realização da PCR.

REALIZAÇÃO DAS TÉCNICAS DE PCR 
Visando confirmar a extração de DNA e atestar a qualidade e integridade do material extraído, além da ausência de inibidores, foi realizada uma PCR para detecção do gene que codifica a enzima gliceraldeído-3-fosfato-desidrogenase (GAPDH), utilizando os oligonucleotídeos GAPDH-F e GAPDH-R (Birkenheuer et al., 2003).

Para a identificação dos hemoplasmas foram utilizados oligonucleotídeos específicos para o gene 16S rRNA. Para a padronização das técnicas de PCR foram utilizados cães e gatos domésticos com diagnóstico laboratorial positivo através de qPCR e sequenciamento. As condições das técnicas de PCR foram determinadas experimentalmente. Amostras desses animais domésticos conhecidamente positivos foram utilizadas como controle positivo, enquanto água miliQ foi utilizada como controle negativo em todas as experimentações.

Para detecção de amostras positivas para hemoplasmas, foram realizadas 6 técnicas diferentes de PCR convencional, uma para gênero de hemoplasmas (utilizando os oligonucleotídeos HBT-F e HBT-R) e outras cinco específicas para M. haemofelis (HF-F1 e HF-R3), Ca. M. haemominutum (1183-F e 1290R), Ca. M. turicensis (CMtFw2 e CmtRev2), M. haemocanis (HCAN-F e HCAN-R) e Ca. M. haematoparvum (HPARV-F e HPARV-R). Também foram realizadas técnicas de PCR para identificação de riquétsias nas amostras, uma geral para a família Anaplasmataceae, capaz de identificar Ehrlichia canis, E. chaffeensis, E. muris, Anaplasma. equi, A. phagocytophila, A. platys, A. marginale, A. centrale, Wolbachia pipientis, E. sennetsu, Neorickettsia risticii e N. helminthoeca (EHR16sd e EHR16sr), uma específica para E. Canis (ECAN5 e HE3) e outra para Anaplasma platys. Nesta última PCR, para A. Platys, foi utilizado um oligonucleotídeo 
específico forward (Platys), combinado com o oligonucleotídeo reverse da PCR para Anaplasmataceae. A descrição dos oligonucleotídeos utilizados em cada PCR encontra-se na tabela 1.

O volume final do mix de cada PCR foi de $25 \mu$ l, contendo tampão de PCR 1X, oligonucleotídeos, $\mathrm{MgCl}_{2}$, dNTP, Taq DNA Polimerase e amostra de DNA. As concentrações de cada reagente e descrição dos ciclos de temperatura para cada técnica encontram-se nas tabelas 2 e 3.

O resultado das PCRs foi analisado por eletroforese em gel de agarose corado com brometo de etídio e observado sob transiluminador de fluorescência.

\section{ANÁLISE ESTATÍSTICA}

Os dados foram inseridos no Microsoft Office Excel ${ }^{\circledR}$ e a análise estatística foi realizada com o auxílio do software SPSS para Windows (SPSS Inc., Chicago, IL, EUA). Variáveis categóricas (gênero, origem, espécie, idade, presença de anemia e resultado da PCR) foram avaliadas por meio do teste qui-quadrado, seguindo um intervalo de confiança de $95 \%$. Os testes Kolmogorov-Smirnov e Shapiro-Wilk foram utilizados para testar a normalidade das variáveis contínuas (VG, número de hemácias e leucócitos). O teste U de Mann-Whitney foi usado para analisar os dados que não seguiam distribuição normal. Resultados foram considerados estatisticamente significativos quando $\mathrm{P}<0,05$. 
RESULTADOS

\section{HEMOPLASMAS EM FELÍDEOS SELVAGENS}

Inicialmente foram comparados os resultados dos hemogramas de animais das diferentes origens, a fim de investigar se a diferença na metodologia de processamento resultou em viés nos resultados. Não foi encontrada diferença, sugerindo que essa divergência não foi fator determinante nos resultados.

Dos 33 felinos testados, 15 (45,5\%) foram positivos para hemoplasmas, sendo duas onças-pintadas, duas jaguatiricas, três gatos-palheiros, quatro onçaspardas, um gato-maracajá, dois jaguarundis e um leão-africano (Tabela 4). Não houve diferença estatística entre animais positivos e negativos quando comparados em relação à instituição de origem, gênero, faixa etária (maior ou menor que 2 anos de idade) ou presença de anemia (Tabelas 5, 6 e 7). Também não houve diferença entre VG, número de hemácias, número de plaquetas e leucograma de animais positivos e negativos. Não foram encontrados quaisquer hemoparasitas nos esfregaços sanguíneos tanto dos animais positivos quanto dos negativos.

Duas onças pintadas foram positivas para $\mathrm{Ca}$. M. haemominutum e $\mathrm{Ca}$. M. haematoparvum, um gato-palheiro para $M$. haemocanis e uma jaguatirica e um gato-palheiro para Ca. M. haematoparvum. Os outros dez felídeos positivos para hemoplasmas não tiveram a espécie detectada pelas técnicas de PCR utilizadas neste trabalho (Tabela 8). 
Dentre os felídeos positivos, uma onça pintada e uma jaguatirica foram positivos para Anaplasma platys, uma onça-parda foi positiva para Ehrlichia canis e uma onça-pintada, uma jaguatirica, dois gatos-palheiros, uma onça-parda e um gato-do-mato-pequeno também foram testados positivos para algum outro agente da família Anaplasmataceae. Dado que os animais foram naturalmente infectados é difícil afirmar qual agente causou a infecção primeiramente. No entanto, é bastante provável que um dos agentes tenha comprometido o sistema imunológico do hospedeiro e favorecido a infecção do outro.

\section{HEMOPLASMAS EM CANÍDEOS SELVAGENS}

Dos 18 canídeos testados, 15 (83,3\%) foram positivos para hemoplasmas, sendo os seis lobos-guarás, quatro raposas-dos-campo, quatro cachorros-do-mato e um cachorro-vinagre (Tabela 9). Não houve diferença entre animais positivos e negativos, quando comparados em relação a gênero, faixa etária ou presença de anemia (Tabelas 5, 6 e 7). Da mesma maneira, não houve diferença na comparação de VG, número de hemácias, número de plaquetas e leucograma de animais positivos e negativos.

Dois cachorros-do-mato foram testados positivos para Ca. M. haemominutum, uma raposa-do-campo e dois cachorros-do-mato foram positivos para M. haemocanis e um cachorro-do-mato-vinagre teve a presença de Ca. M. haematoparvum. Ainda assim, nove canídeos positivos não tiveram a espécie de hemoplasma detectada pelas técnicas de PCR aqui utilizadas (Tabela 8). 
Não foi detectada coinfecção das espécies de hemoplasmas estudadas em nenhuma amostra de canídeos, no entanto, dentre as amostras positivas para hemoplasmas um lobo-guará e uma raposa-do-campo foram positivos para $A$. platys e E. canis; um cachorro-do-mato, uma raposa-do-campo e três lobos-guarás foram positivos para $A$. platys; uma raposa-do-campo e um lobo-guará testaram positivo para E. canis; e um cachorro-do-mato, duas raposas-do-campo e um loboguará foram positivos para algum agente da família Anaplasmataceae não especificado. No esfregaço sanguíneo do lobo-guará positivo para $E$. canis foi encontrada uma mórula em plaqueta, contudo não foram encontrados hemoplasmas nos esfregaços de quaisquer dos canídeos estudados. 


\section{DISCUSSÃO}

\section{HEMOPLASMAS EM FELÍDEOS SELVAGENS}

Outros trabalhos foram realizados investigando a infecção por hemoplasmas em felídeos selvagens nos últimos anos e a ocorrência do agente diverge consideravelmente em cada pesquisa. Em um estudo realizado com 54 felídeos de cativeiro de Illinois e da Flórida, nos Estados Unidos, teve apenas dois $(0,04 \%)$ tigres positivos (Haefner et al., 2003). Este valor é bem inferior aos 45,5\% encontrados no presente trabalho, apesar de também se tratarem de animais de cativeiro.

A Fundação Jardim Zoológico de Brasília encontra-se em um grande centro populacional e, por este motivo, enfrenta um grande problema com gatosdomésticos errantes e animais sinantrópicos, tais como capivaras. Os gatos e capivaras tem livre acesso ao parque e podem ser responsáveis pelo trânsito de vetores para dentro e fora do parque e manutenção dos altos índices de infecção nos espécimes selvagens. São necessários estudos com esses animais e seus vetores para ter certeza de seu papel neste ciclo.

Outro estudo, realizado com 165 felídeos oriundos de zoológicos de São Paulo, Mato Grosso e Distrito Federal a ocorrência da infecção por hemoplasmas foi de $13,9 \%$ em felídeos, totalizando 23 animais infectados. Do total de animais, dez pertenciam à Fundação Jardim Zoológico de Brasília e três (30\%) deles testaram positivo para Ca. M. haemominutum (André et al., 2011). Apesar da 
ocorrência total ser bem menor, quando se considera apenas os animais do Distrito Federal, embora tenham sido amostrados apenas dez animais, há maior proximidade em relação à ocorrência encontrada no presente trabalho, ainda que permaneça menor. Isso sugere tanto que a infecção por hemoplasmas em felídeos selvagens pode ser mais frequente no Distrito Federal que em Mato Grosso e São Paulo, quanto que esta vem crescendo com o passar dos anos, tendo passado de $30 \%$ para $45,5 \%$. Este problema pode estar mais uma vez relacionado aos animais errantes, cada vez mais frequentes nas imediações do Zoológico de Brasília.

Um terceiro trabalho que avaliou amostras de sangue e fluidos serossanguinolentos de 257 felídeos selvagens de 15 espécies diferentes oriundos de vida-livre ou cativeiro na África, América do Sul e Europa obteve 96 animais positivos (37\%) para a infecção por hemoplasmas. Os felídeos foram divididos em cinco grupos com diferentes frequências de infecção: leões do Serengeti (98\%), linces-euroasiáticos (44\%), felídeos selvagens europeus (39\%), linces-ibéricos (37\%) e felídeos selvagens brasileiros (10\%) (Willi et al., 2007). Apesar da ocorrência total ser bastante próxima da encontrada neste trabalho, existe uma disparidade considerável quando se compara apenas os felídeos selvagens brasileiros. Os autores insinuam que a diferença na frequência de infecção entre os cinco grupos estudados pode ser devido a diferença nos ambientes onde vivem os animais, tanto de um cativeiro para outro, quanto de cativeiro para vida-livre. Deve-se considerar, portanto, que as amostras dos felídeos selvagens brasileiros foram colhidas no Parque Zoológico de São Paulo, situado na Mata Atlântica brasileira, enquanto as amostras do presente trabalho foram colhidas de animais que vivem no Cerrado brasileiro. As diferenças entre esses dois ecossistemas podem influenciar em fatores como a variação de temperatura, facilitando ou 
dificultando que os animais sofram estresse térmico, bem como alterando a suscetibilidade a ectoparasitas que potencialmente veiculam o agente em questão. Isso pode justificar a variação de $35,5 \%$ na frequência de infecção entre os trabalhos.

A infecção de felinos domésticos representa um potencial patogênico já avaliado anteriormente (Sukura et al., 1991; Foley et al., 1998), porém isso não tem sido frequentemente relatado em felídeos selvagens (Willi et al., 2007; André et al., 2011). É possível chegar às hipóteses de que os animais encontravam-se no estágio crônico da infecção, foram infectados por linhagens menos patogênicas do agente, ou ainda possuíam melhor imunocompetência e, portanto, não apresentaram anemia (Tasker et al., 2003b; Willi et al., 2006; Aquino et al., 2014). Umas das onças-pardas positivas para Ca. M. haemominutum e Ca. M. haematoparvum teve sua amostra testada duas vezes no intervalo de um ano e foi positiva em ambos os testes. Esse dado ratifica a teoria deste animal encontrar-se na fase crônica de infecção e aumenta a probabilidade de o mesmo estar acontecendo com os outros indivíduos testados.

Estudos com felinos domésticos indicam que a infecção por hemoplasmas é mais frequente em machos que em fêmeas, e que $M$. haemofelis é mais frequente em animais jovens, enquanto $\mathrm{Ca}$. M. haemominutum é mais relatado em animais mais velhos (Willi et al., 2006; Sykes \& Tasker, 2013). Contudo, da mesma forma que o presente trabalho, Willi et al., 2007 não encontrou correlação entre gênero e infecção por hemoplasmas em outro trabalho investigando felídeos selvagens.

A coinfecção por diferentes espécies de hemoplasmas é frequentemente relatada em gatos domésticos (Tasker et al., 2003a; Willi et al., 2006; Aquino et al., 2014). O percentual de animais infectados concomitantemente com mais de uma 
espécie de hemoplasmas foi de $21,4 \%$ em um trabalho que investigou apenas a presença de $M$. haemofelis, Ca. M. haemominutum e Ca. M. turicensis em felídeos selvagens. (Willi et al., 2007) Curiosamente, apenas duas onças-pardas apresentaram infecção simultânea por mais de uma espécie de hemoplasma, sendo nos dois casos $\mathrm{Ca}$. M. haemominutum e Ca. M. haematoparvum. Vale ressaltar que existe uma proximidade muito grande entre essas duas espécies e que as duas técnicas de PCR podem estar identificando um mesmo agente (Willi et al., 2006). É necessário fazer o sequenciamento das mostras positivas para esclarecer esta dúvida, assim como para identificar as amostras positivas sem espécie identificada, mas o uso desta técnica não foi possível.

Este é o primeiro trabalho de conhecimento dos autores a relatar a infecção por M. haemocanis e Ca. M. haematoparvum em felídeos selvagens. No entanto, é preciso reiterar que, devido à similaridade genética entre $M$. haemofelis e $M$. haemocanis e entre $C a$. M. haemominutum e Ca. M. haematoparvum, é necessário que as amostras positivas sejam sequenciadas para confirmação (Sykes \& Tasker, 2013).

\section{HEMOPLASMAS EM CANÍDEOS SELVAGENS}

A infecção por hemoplasmas em cães domésticos já foi descrita na literatura, especialmente associada a animais esplenectomizados ou imunossuprimidos. Um estudo com 889 cães na Suíça encontrou uma ocorrência da infecção por $M$. haemocanis ou Ca. M. haematoparvum de 1,2\%, sendo a do primeiro agente 0,9\% 
e a do segundo $0,3 \%$ (Wengi et al., 2008). Outro estudo pesquisou os mesmos agentes em 154 cães de Ribeirão Preto e encontrou uma ocorrência de hemoplasmas caninos de 2,5\%, sendo $1,9 \%$ das infecções por $M$. haemocanis e 0,6\% por Ca. M. haematoparvum (Alves et al., 2014). A ocorrência encontrada nos animais do presente trabalho ultrapassam significativamente a encontrada em ambos os trabalhos, seja pela diferença da espécies de hospedeiro avaliadas, de agentes infecciosos investigadas ou da disponibilidade de vetores no ambiente.

Um estudo investigou a ocorrência de hemoplasmas em 100 canídeos selvagens, sendo três lobos europeus (Canis lupus) e 97 canídeos silvestres brasileiros mantidos em cativeiro em zoológicos de São Paulo, Mato Grosso e Distrito Federal. A frequência da infecção por hemoplasmas foi calculada em 4\%, sendo bastante inferior à de $83,3 \%$ encontrada no presente trabalho. No entanto, dois lobos $(2 \%)$ testaram positivos para $\mathrm{Ca}$. M. haemominutum, e dois cachorrosdo-mato-vinagre (2\%) para Ca. M. haematoparvum. No presente trabalho dois cachorros-do-mato $(11,1 \%)$ também foram positivos para Ca. M. haemominutum e um cachorro-do-mato-vinagre foi positivo para Ca. M. haematoparvum (André et al., 2011).

Cabe observar que todos os canídeos avaliados vieram de uma mesma instituição e que o alto índice de infecção pode ser consequência, não apenas de condições ecológicas da região, mas também de condições sanitárias locais. Mais uma vez, a dificuldade no controle de vetores de animais errantes e sinantrópicos pode ter sido determinante neste caso e precisa de estudos mais direcionados.

Curiosamente, todos os lobos-guarás foram positivos para hemoplasmas e riquétsias. Os animais vivem em recintos próximos uns dos outros e que se comunicam por grades, o que certamente é um fator que propicia a transmissão 
dos agentes. Ainda assim a espécie de hemoplasma de nenhum deles foi detectada, mas três indivíduos foram positivos para A. platys, um para E. canis e um para A. platys e E. canis, revelando-se triplamente infectado. Este animal, uma fêmea filhote, apresentou anemia e veio a óbito com aproximadamente dois meses de vida. Outro lobo-guará, nascido na mesma ninhada, mas positivo apenas para gênero de hemoplasma e $A$. platys, apresentou trombocitopenia além de anemia. Quatro meses depois o animal foi diagnosticado com uma doença osteometabólica e sofreu eutanásia.

Dentre os animais estudados também encontrou-se uma raposa-do-campo com tripla infecção. Diferentemente do lobo-guará, esta apresentou apenas trombocitopenia, sem qualquer sinal ao exame físico.

Este trabalho converge com outros que investigaram a infecção por hemoplasmas em canídeos, tanto domésticos quanto selvagens, ao evidenciar que hemoplasmas possuem baixa patogenicidade nessas espécies, não correlacionando anemia ou qualquer outro achado hematológico à infecção (Wengi et al., 2008; André et al., 2011; Alves et al., 2014). Vale ressaltar que mesmo os animais coinfectados com riquétsias não apresentaram alterações hematológicas estatísticamente significativas em relação aos animais não infectados.

Estudos com cães domésticos também apontam que não existe correlação entre infecção por hemoplasmas e gênero ou faixa etária (Wengi et al., 2008), mas nenhum outro estudo com canídeos selvagens tentou estabelecer esta comparação.

Este é o primeiro trabalho a identificar M. haemocanis infectando canídeos selvagens do conhecimento dos autores. Contudo, é preciso ressaltar mais uma vez a semelhança entre os genomas de $M$. haemocanis e $M$. haemofelis, sobretudo 
no gene 16S rRNA, e que é preciso realizar o sequenciamento das amostras positivas para distinção entre as espécies (Sykes \& Tasker, 2013). 


\section{CONCLUSÕES}

A infecção por hemoplasmas é frequente em carnívoros selvagens de cativeiro, tendo uma ocorrência de $45,5 \%$ em felídeos e $83,3 \%$ em canídeos. No entanto, não são encontrados achados hematológicos significativos em aniamais positivos, levando a crer que a hemoplasmose não costuma aparecer como doença nestes animais, possivelmente em decorrência destes serem cronicamente infectados ou parasitados por espécies ou linhagens menos patogênicas do agente.

A espécie mais frequentemente encontrada em felídeos foi $\mathrm{Ca}$. M. haematoparvum, enquanto a mais frequente em canídeos foi $M$. haemocanis, com uma ocorrência de 12,1\% e 16,7\%, respectivamente. Por outro lado, as espécies menos frequentes foram $M$. haemofelis e Ca. M. turicensis, não encontradas em nenhum dos espécimes analisados.

A transmissão de hemoplasmas felinos parece funcionar de maneira diferente em animais selvagens uma vez que fatores como gênero e faixa etária não se correlacionam com a infecção. Em canídeos, por outro lado, não parece haver divergência entre animais domésticos e selvagens neste quesito.

Além disso, a alta ocorrência de hemoplasmas nestes animais selvagens oriundos de grandes centros populacionais implica que estes podem agir como reservatórios do agente e perpetuar a infecção de animais domésticos.

Mostra-se necessário o emprego de outras técnicas moleculares, como o sequenciamento genético, a fim de elucidar se os indivíduos parasitados sem identificação da espécie tratam-se apenas de pequenas mutações no genoma dos parasitas ou se existem novas espécies infectando carnívoros selvagens. 


\section{REFERÊNCIAS BIBLIOGRÁFICAS}

Alves, T. B., S. A. Faggion, E. V. Santos, P. G. Roberto, S. C. França, A. L. FACHIN, AND M. MARINS. 2014. Estudio de micoplasmas hemotróficos en perros de Ribeirão Preto, Brasil, basado en la PCR en tiempo real. Archivos de medicina veterinaria 46 : 333-336.

André, M. R., C. H. Adania, S. M. Allegretti, and R. Z. Machado. 2011. Hemoplasmas in wild canids and felids in Brazil. Journal of zoo and wildlife medicine: official publication of the American Association of Zoo Veterinarians 42: 342-347.

Aquino, L. C., C. A. E. Hicks, M. C. Scalon, M. G. DA M. LimA, M. DOS S. LemOS, G. R. Paludo, C. R. Helps, e S. TAsker. 2014. Prevalence and phylogenetic analysis of haemoplasmas from cats infected with multiple species. Journal of Microbiological Methods 107: 189-196.

Biondo, A. W., A. P. dos Santos, A. M. S. Guimarães, R. F. DA C. VieIRA, O. Vidotto, D. De B. Macieira, N. R. P. Almosny, M. B. Molento, J. Timenetsky, H. A. DE Morais, D. GonZÁlezZ, F. HILÁRIO, AND J. B. MesSICK. 2009. A review of the occurrence of hemoplasmas (hemotrophic mycoplasmas) in Brazil. Revista Brasileira de Parasitologia Veterinária 18: 1-7.

BiRKENHEUeR, A. J., M. G. LeVY, AND E. B. BREITSCHWERDT. 2003. Development and evaluation of a seminested PCR for detection and differentiation of Babesia gibsoni (Asian genotype) and B. canis DNA in canine blood samples. Journal of Clinical Microbiology 41: 4172-4177. 
Criado-Fornelio, A., A. Martinez-Marcos, A. Buling-Saraña, and J. C. BarbaCarretero. 2003. Presence of Mycoplasma haemofelis, Mycoplasma haemominutum and piroplasmids in cats from southern Europe: a molecular study. Veterinary Microbiology 93: 307-317.

Foley, J. E., S. Harrus, A. Poland, B. Chomel, and N. C. Pedersen. 1998. Molecular, clinical, and pathologic comparison of two distinct strains of Haemobartonella felis in domestic cats. American journal of veterinary research 59: 1581-1588.

Guimaraes, A. M. S., M. L. Javorouski, M. Bonat, O. Lacerda, B. Balbinotti, L. G. P. B. Queiroz, J. Timenetsky, A. W. Biondo, And J. B. Messick. 2007. Molecular detection of "Candidatus Mycoplasma haemominutum" in a lion (Panthera leo) from a brazilian zoological garden. Revista do Instituto de Medicina Tropical de São Paulo 49: 195-196.

Haefner, M., T. J. Burke, B. E. Kitchell, L. A. Lamont, D. J. Schaeffer, M. Behr, AND J. B. MEssick. 2003. Identification of Haemobartonella felis (Mycoplasma haemofelis) in captive nondomestic cats. Journal of Zoo and Wildlife Medicine 34: 139-143.

Maggi, R. G., P. E. Mascarelli, L. N. Havenga, V. Naidoo, and E. B. BREITSCHWERDT. 2013. Co-infection with Anaplasma platys, Bartonella henselae and Candidatus Mycoplasma haematoparvum in a veterinarian. Parasites \& Vectors 6: 103

SANTOS, A. P. D. 2009. Infecção por hemoplasmas em felinos domésticos na região de Porto Alegre, RS, Brasil. Acta Scientiae Veterinariae 37: 95-96. 
SukURA, A., Y. T. Gröhn, J. JUNTtILA, AND T. PALOLAHTI. 1991. Association between feline immunodeficiency virus antibodies and host characteristics in Finnish cats. Acta veterinaria Scandinavica 33: 325-334.

SYKeS, JANE E. \& TASKER, SÉVERINE. 2013. Hemoplasma infections. In Canine and Feline Infectious Diseases. Elsevier Health Sciences. pp. 390-8.

Tasker, S., S. H. Binns, M. J. Day, T. J. Gruffydd-Jones, D. A. Harbour, C. R. Helps, W. A. Jensen, C. S. Olver, and M. R. LAppin. 2003a. Use of a PCR assay to assess the prevalence and risk factors for Mycoplasma haemofelis and "Candidatus Mycoplasma haemominutum" in cats in the United Kingdom. Veterinary Record 152: 193-198.

Tasker, S., C. R. Helps, M. J. Day, T. J. Gruffydd-Jones, and D. A. Harbour. 2003b. Use of Real-Time PCR To Detect and Quantify Mycoplasma haemofelis and "Candidatus Mycoplasma haemominutum" DNA. Journal of Clinical Microbiology 41: 439-441.

Tasker, S., C. R. Helps, M. J. Day, D. A. Harbour, S. E. Shaw, S. Harrus, G. Baneth, R. G. Lobetti, R. Malik, J. P. Beaufils, C. R. Belford, and T. J. GRUFFYDD-JONES. 2003c. Phylogenetic Analysis of Hemoplasma Species: an International Study. Journal of Clinical Microbiology 41: 3877-3880.

The IUCN Red List of Threatened Species. Version 2015-4. <www.iucnredlist.org>. Downloaded on 01 January 2016.

Thrall, M. A. 2007. Anemia Regenerativa. In Hematologia e Bioquímica Clínica Veterinária. Roca. pp. 89-113.

Torkan, S., S. J. Aldavood, A. Sekhavatmandi, and S. MoshKelani. 2012. Detection of haemotropic Mycoplasma (Haemobartonella) using multiplex 
PCR and its relationship with epidemiological factors in dogs. Comparative Clinical Pathology 23: 669-672.

Wengl, N., B. Willi, F. S. Boretti, V. Cattori, B. Riond, M. L. Meli, C. E. Reusch, H. LUtZ, AND R. HOFMANN-LEHMANN. 2008. Real-time PCR-based prevalence study, infection follow-up and molecular characterization of canine hemotropic mycoplasmas. Veterinary Microbiology 126: 132-141.

Willi, B., F. S. Boretti, C. Baumgartner, S. Tasker, B. Wenger, V. Cattori, M. L. Meli, C. E. Reusch, H. Lutz, and R. Hofmann-LehmanN. 2006. Prevalence, Risk Factor Analysis, and Follow-Up of Infections Caused by Three Feline Hemoplasma Species in Cats in Switzerland. Journal of Clinical Microbiology 44: 961-969.

Willi, B., C. Filoni, J. L. Catão-Dias, V. Cattori, M. L. Meli, A. Vargas, f. Martínez, M. E. Roelke, M.-P. Ryser-Degiorgis, C. M. Leutenegger, H. LUTZ, AND R. HOFMANN-LEHMANN. 2007. Worldwide Occurrence of Feline Hemoplasma Infections in Wild Felid Species. Journal of Clinical Microbiology 45: 1159-1166. 


\section{TABELAS}

Tabela 1. Oligonucleotídeos utilizados no controle da extração de DNA e na investigação e identificação de hemoplasmas

\begin{tabular}{|c|c|c|c|c|}
\hline $\begin{array}{c}\text { Nome do } \\
\text { oligonucleotídeo }\end{array}$ & Sequência do oligonucleotídeo & $\begin{array}{c}\text { Temperatura } \\
\text { de melting }\left({ }^{\circ} \mathrm{C}\right)\end{array}$ & $\begin{array}{l}\text { Tamanho do } \\
\text { produto (pb) }\end{array}$ & $\begin{array}{c}\text { Referência } \\
\text { bibliográfica }\end{array}$ \\
\hline$G A P D H-F$ & CCT TCA TTG ACC TCA ACT ACA T & 62 & \multirow[t]{2}{*}{400} & \multirow{2}{*}{$\begin{array}{l}\text { (Birkenheuer et } \\
\text { al., 2003) }\end{array}$} \\
\hline$G A P D H-R$ & CCA AAG TTG TCA TGG ATG ACC & 62 & & \\
\hline$H B T-F$ & ATA CGG CCC ATA TTC CTA CG & 60 & \multirow[t]{2}{*}{595} & \multirow{2}{*}{$\begin{array}{l}\text { (Criado-Fornelio } \\
\text { et al., 2003) }\end{array}$} \\
\hline$H B T-R$ & TGC TCC ACC ACT TGT TCA & 54 & & \\
\hline$H F-F 1$ & GAC TTT GGT TTC GGC CAA GG & 62 & 393 & $\begin{array}{l}\text { (Criado-Fornelio } \\
\text { et al., 2003) }\end{array}$ \\
\hline $1183-F$ & GCA TAA TGT GTC GCA ATC & 52 & \multirow[t]{2}{*}{169} & \multirow{2}{*}{$\begin{array}{l}\text { (Criado-Fornelio } \\
\text { et al., 2003) }\end{array}$} \\
\hline $1290 R$ & GTT TCA ACT AGT ACT TTC TCC & 58 & & \\
\hline CMtFw2 & GTC CTA TAG TAT CCT CCA TCA GAC AG & 76 & \multirow[t]{2}{*}{1039} & \multirow{2}{*}{$\begin{array}{c}\text { (Aquino et al., } \\
\text { 2014) }\end{array}$} \\
\hline CMtRev2 & CGA CAC ATT GTA CTC ACC ATT GTA A & 70 & & \\
\hline$H C A N-F$ & GAA ACT AAG GCC ATA AAT GAC GC & 66 & 309 & $\begin{array}{l}\text { (Torkan et al., } \\
\text { 2012) }\end{array}$ \\
\hline EHR16sr & TAG CAC TCA TCG TTT ACA GC & 58 & 345 & $\begin{array}{l}\text { (Inokuma et al., } \\
\text { 2001) }\end{array}$ \\
\hline ECAN5 & TAT AGG TAC CGT CAT TAT CTT CCC TAT & 74 & \multirow[t]{2}{*}{396} & \multirow{2}{*}{$\begin{array}{c}\text { (Inokuma et al., } \\
\text { 2001) }\end{array}$} \\
\hline HE3 & CAA TTA TTT ATA GCC TCT GGC TAT AGG A & 76 & & \\
\hline Platys & GAT TTT TGT CGT AGC TTG CTA TG & 64 & 678 & $\begin{array}{c}\text { (Inokuma et al., } \\
2001 \text { ) }\end{array}$ \\
\hline
\end{tabular}


Tabela 2. Concentração/ volume de reagentes utilizados nas diferentes técnicas de PCR.

\begin{tabular}{|r|c|c|c|c|c|}
\hline & $\begin{array}{r}\text { Oligonucletídeos } \\
(\boldsymbol{\mu M})\end{array}$ & $\begin{array}{c}\mathbf{M g C l}_{2} \\
(\mathbf{m M})\end{array}$ & $\begin{array}{c}\mathbf{d N T P} \\
(\mathbf{m M})\end{array}$ & $\begin{array}{c}\text { Taq DNA } \\
\text { Polimerase } \\
(\mathbf{U})\end{array}$ & $\begin{array}{c}\text { Amostra } \\
\text { de DNA } \\
(\boldsymbol{\mu l})\end{array}$ \\
\hline Gênero de hemoplasma & 0,5 & 2,5 & 0,20 & 1,25 & 1 \\
\hline $\boldsymbol{M}$. haemofelis & 0,1 & 2,5 & 0,20 & 1,25 & 1 \\
\hline Ca. M. haemominutum & 0,1 & 2,5 & 0,25 & 1,25 & 1 \\
\hline Ca. M. turicensis & 0,2 & 2,5 & 0,25 & 1,25 & 1 \\
\hline M. haemocanis & 0,2 & $1 X^{*}$ & 0,25 & 1,25 & 1 \\
\hline Ca. M. haematoparvum & 0,2 & $1 X^{*}$ & 0,25 & 1,25 & 1 \\
\hline Anaplasmataceae & 1 & 1,6 & 0,25 & 0,5 & 5 \\
\hline E. canis & 0,25 & 2,0 & 0,20 & 0,5 & 1 \\
\hline A. platys & 1 & 1,6 & 0,25 & 0,5 & 5 \\
\hline
\end{tabular}

${ }^{*} \mathrm{O} \mathrm{MgCl} 2$ já se encontra adicionado ao tampão do fabricante da Taq DNA Polimerase utilizada. 
Tabela 3. Condições para amplificação dos diferentes agentes. (T: temperatura; D: duração)

\begin{tabular}{|c|c|c|c|c|c|c|c|c|c|c|c|}
\hline & \multicolumn{2}{|c|}{$\begin{array}{c}\text { Desnaturação } \\
\text { inicial }\end{array}$} & \multirow{2}{*}{$\begin{array}{l}\mathrm{N}^{\mathbf{0}} \mathrm{de} \\
\text { ciclos }\end{array}$} & \multicolumn{2}{|c|}{ Desnaturação } & \multicolumn{2}{|c|}{ Anelameto } & \multicolumn{2}{|c|}{ Extensão } & \multicolumn{2}{|c|}{ Extensão final } \\
\hline & $\mathrm{T}\left({ }^{\circ} \mathrm{C}\right)$ & $\mathrm{D}(\mathrm{s})$ & & $\mathrm{T}\left({ }^{\circ} \mathrm{C}\right)$ & $\mathrm{D}(\mathrm{s})$ & $\mathrm{T}\left({ }^{\circ} \mathrm{C}\right)$ & $\mathrm{D}(\mathrm{s})$ & $\mathrm{T}\left({ }^{\circ} \mathrm{C}\right)$ & $\mathrm{D}(\mathrm{s})$ & $\mathrm{T}\left({ }^{\circ} \mathrm{C}\right)$ & $\mathrm{D}(\mathrm{s})$ \\
\hline $\begin{array}{r}\text { Gênero de } \\
\text { hemoplasma }\end{array}$ & 94 & 600 & 40 & 94 & 30 & 56 & 30 & 72 & 30 & 72 & 600 \\
\hline M. haemofelis & 94 & 600 & 43 & 94 & 45 & 54 & 30 & 72 & 30 & 72 & 420 \\
\hline $\begin{array}{r}\text { Ca. M. } \\
\text { haemominutum }\end{array}$ & 94 & 240 & 35 & 94 & 30 & 53 & 60 & 72 & 45 & 75 & 300 \\
\hline Ca. M. turicensis & 95 & 300 & 40 & 95 & 10 & 59 & 30 & 72 & 90 & 72 & 300 \\
\hline M. haemocanis & 94 & 300 & 34 & 94 & 60 & 60 & 60 & 72 & 60 & 72 & 300 \\
\hline $\begin{array}{r}\text { Ca. M. } \\
\text { haematoparvum }\end{array}$ & 94 & 300 & 35 & 94 & 60 & 60 & 60 & 72 & 60 & 72 & 300 \\
\hline Anaplasmataceae & 95 & 300 & 34 & 95 & 30 & 53 & 30 & 72 & 90 & 72 & 300 \\
\hline E. canis & 94 & 180 & 40 & 94 & 60 & 63 & 120 & 72 & 90 & 72 & 300 \\
\hline A. platys & 95 & 300 & 40 & 95 & 30 & 51 & 30 & 72 & 90 & 72 & 300 \\
\hline
\end{tabular}


Tabela 4. Resultado da PCR geral para hemoplasmas por espécie de felídeos

\begin{tabular}{|r|c|c|c|}
\hline & $\begin{array}{c}\text { Número (\%) } \\
\text { de positivos }\end{array}$ & $\begin{array}{c}\text { Número (\%) de } \\
\text { negativos }\end{array}$ & Total \\
\hline Leopardus wiedii & $1(3)$ & $1(3)$ & $2(6)$ \\
\hline Panthera onca & $2(6,1)$ & $9(27,3)$ & $11(33,4)$ \\
\hline Leopardus pardalis & $2(6,1)$ & $0(0)$ & $2(6,1)$ \\
\hline Leopardus pajerus & $3(9,1)$ & $0(0)$ & $3(9,1)$ \\
\hline Puma concolor & $4(12,1)$ & $2(6,1)$ & $6(18,2)$ \\
\hline Panthera tigris & $0(0)$ & $4(12,1)$ & $4(12,1)$ \\
\hline Puma yagouaroundi & $2(6,1)$ & $1(3)$ & $3(9,1)$ \\
\hline Panthera leo & $1(3)$ & $1(3)$ & $2(6)$ \\
\hline Total & $15(45,5)$ & $18(54,5)$ & $33(100)$ \\
\hline
\end{tabular}

Tabela 5. Número (\%) de animais positivos e negativos para infecção por hemoplasmas correlacionados com gênero pelo teste Qui-quadrado de Pearson

\begin{tabular}{|c|c|c|c|c|}
\hline & \multicolumn{4}{|c|}{ Gênero } \\
\hline \multirow{2}{*}{$\begin{array}{l}\text { PCR para } \\
\text { hemoplasmas }\end{array}$} & \multicolumn{2}{|c|}{ Felídeos } & \multicolumn{2}{|c|}{ Canídeos } \\
\hline & Macho & Fêmea & Macho & Fêmea \\
\hline Negativo & $7(21,2) a$ & $11(33,3) a$ & $1(5,6)$ a & $2(11,1) a$ \\
\hline Positivo & $10(30,3)_{a}$ & $5(15,2)$ a & $9(50)_{a}$ & $6(33,3) a$ \\
\hline Total & $17(51,5)$ & $16(48,5)$ & $10(55,6)$ & $8(44,4)$ \\
\hline
\end{tabular}

(Felídeos: $p=0.112$; Canídeos: $p=0,396$ ). Letras subscritas iguais em colunas diferentes indicam que as proporções não diferem significativamente entre si. 
Tabela 6. Número (\%) de animais positivos e negativos para infecção por hemoplasmas correlacionados com a faixa etária pelo teste Qui-quadrado de Pearson

\begin{tabular}{|l|c|c|c|c|}
\hline & \multicolumn{4}{|c|}{ Faixa etária } \\
\hline $\begin{array}{l}\text { PCR para } \\
\text { hemoplasmas }\end{array}$ & \multicolumn{2}{|c|}{ Felídeos } & \multicolumn{2}{c|}{ Canídeos } \\
\hline & $<2 a n o s$ & $>2 a n o s$ & $<2$ anos & $>2$ anos \\
\hline Negativo & $2(6,1)$ a & $16(48,5)$ a & $1(5,6)$ a & $2(11,1)$ a \\
\hline Positivo & $1(3)_{a}$ & $14(42,4) a$ & $5(27,8)$ a & $10(55,5)$ a \\
\hline Total & $3(9,1)$ & $30(90,9)$ & $6(33,4)$ & $12(66,6)$ \\
\hline
\end{tabular}

(Felídeos: $p=0,658$; Canídeos: $p=1,000$ ). Letras subscritas iguais em colunas diferentes indicam que as proporções não diferem significativamente entre si.

Tabela 7. Número (\%) de felídeos positivos e negativos para infecção por hemoplasmas correlacionados com a presença ou não de anemia $(V G<25)$ pelo teste Qui-quadrado de Pearson

\begin{tabular}{|l|c|c|c|c|}
\hline & \multicolumn{4}{|c|}{ Anemia } \\
\hline $\begin{array}{c}\text { PCR para } \\
\text { hemoplasmas }\end{array}$ & \multicolumn{2}{|c|}{ Felídeos } & \multicolumn{2}{c|}{ Canídeos } \\
\hline & $V G \geq 27$ & $V G<27$ & $V G \geq 38$ & $V G<38$ \\
\hline Negativo & $12(50) a$ & $1(4,2) a$ & $2(12,5) a$ & $1(6,3) a$ \\
\hline Positivo & $10(41,7) a$ & $1(4,2) a$ & $4(25) a$ & $9(56,2) a$ \\
\hline Total & $22(91,7)$ & $2(8,4)$ & $6(37,5)$ & $10(62,5)$ \\
\hline
\end{tabular}

(Felídeos: $p=0,902$; Canídeos: $p=0,247$ ). Letras subscritas iguais em colunas diferentes indicam que as proporções não diferem significativamente entre si. 
Tabela 8. Número (\%) de animais positivos e negativos para as técnicas de PCR realizadas.

\begin{tabular}{|r|c|c|c|c|}
\hline & \multicolumn{2}{|c|}{ Felídeos } & \multicolumn{2}{c|}{ Canídeos } \\
\hline $\begin{array}{r}\text { Gênero de } \\
\text { hemoplasma }\end{array}$ & $15(45,5)$ & $18(54,5)$ & $15(83,3)$ & $3(16,7)$ \\
\hline $\begin{array}{r}\text { M. haemofelis } \\
\text { Pa. M. }\end{array}$ & $0(0)$ & $33(100)$ & $0(0)$ & $18(100)$ \\
\hline $\begin{array}{r}\text { haemominutum } \\
\text { haem. }\end{array}$ & $0(0,1)$ & $31(93,9)$ & $2(11,1)$ & $16(88,9)$ \\
\hline $\begin{array}{r}\text { Ca. M. } \\
\text { turicensis }\end{array}$ & $33(100)$ & $0(0)$ & $18(100)$ \\
\hline M. haemocanis & $1(3)$ & $32(97)$ & $3(16,7)$ & $15(83,3)$ \\
\hline $\begin{array}{r}\text { Ca. M. } \\
\text { haematoparvum }\end{array}$ & $4(12,1)$ & $29(87,9)$ & $1(5,6)$ & $17(94,4)$ \\
\hline
\end{tabular}

Tabela 9. Resultado da PCR geral para hemoplasmas por espécie de canídeos

\begin{tabular}{|r|c|c|c|}
\hline & $\begin{array}{c}\text { Número (\%) } \\
\text { de positivos }\end{array}$ & $\begin{array}{c}\text { Número (\%) de } \\
\text { negativos }\end{array}$ & Total \\
\hline $\begin{array}{r}\text { Chrysocyon } \\
\text { brachyrurus }\end{array}$ & $6(33,3)$ & $0(0)$ & $6(33)$ \\
\hline Lycalopex vetulus & $4(22,2)$ & $1(5,6)$ & $5(27,8)$ \\
\hline Cerdocyon thous & $4(22,2)$ & $1(5,6)$ & $5(27,8)$ \\
\hline Speothos venaticus & $1(5,6)$ & $1(5,6)$ & $6(11,2)$ \\
\hline Total & $15(83,3)$ & $3(16,7)$ & $33(100)$ \\
\hline
\end{tabular}

